\title{
POTENCIAL FISIOLÓGICO DAS SEMENTES DE Vigna radiata PRODUZIDAS EM DIFERENTES DENSIDADES POPULACIONAIS
}

Edvan Costa da Silva ${ }^{1}$, Nei Peixoto $^{2}$, Natália Arruda $^{3}$, Natália Cássia de Faria Ferreira ${ }^{4}$, Luciana Sabini da Silva ${ }^{5}$ Willian dos Reis ${ }^{5}$, Wagner Menechini ${ }^{1}$, Carolina dos Santos Galvão ${ }^{4}$

\begin{abstract}
RESUMO - O presente trabalho teve como objetivo avaliar a qualidade fisiológica de sementes de feijão mungo em função do espaçamento entre fileiras e número de plantas por metro linear. O experimento foi conduzido na Universidade Estadual de Goiás, Câmpus Ipameri, utilizando-se sementes produzidas no mesmo local. Para avaliação da qualidade fisiológica das sementes foram realizados testes para determinação do teor de água, germinação e vigor. As análises foram realizadas no laboratório Multidisciplinar II. O delineamento experimental utilizado foi inteiramente casualizado, com os tratamentos dispostos em esquema fatorial $2 \times 6$, tendo como fatores os espaçamentos entre fileiras $(25$ e $50 \mathrm{~cm})$ e números de plantas por metro linear $(4,8,12,16,20$ e 24 plantas), com quatro repetições. Os testes foram realizados com sementes armazenadas durante seis meses. De acordo com os resultados da análise de variância, na primeira contagem de germinação, comprimento de parte aérea, comprimento de raiz e condutividade elétrica houve interação significativa entre os fatores estudados. A massa seca de plântulas apresentou efeito significativo para os espaçamentos entre fileiras e números de plantas por metro linear de forma isolada. Para a massa de mil sementes, envelhecimento acelerado, emergência de plântulas em areia e índice de velocidade de emergência, verificou-se efeito significativo isolado apenas para os espaçamentos entre fileiras. A germinação não foi influenciada pelos espaçamentos entre fileiras e números de plantas por metro linear. O espaçamento entre fileiras de $50 \mathrm{~cm}$, com 24 plantas $\mathrm{m}^{-1}$ linear entre fileiras, apresentaram melhor potencial fisiológico, evidenciado pela massa de mil sementes e condutividade elétrica. As sementes de feijão mungo produzidas em 24 plantas $\mathrm{m}^{-1}$ linear e espaçamento de $50 \mathrm{~cm}$ entre fileiras, apresentam melhor potencial fisiológico.
\end{abstract}

Palavras chave: arranjo de plantas, feijão mungo, germinação, vigor de sementes.

\section{PHYSIOLOGICAL POTENTIAL OF Vigna radiata SEEDS PRODUCED IN DIFFERENT POPULATION DENSITIES}

\begin{abstract}
This work aimed to evaluate the physiological quality of mung bean seeds as a function of row spacing and number of plants per linear meter. The experiment was conducted at the State University of Goiás, Câmpus Ipameri, using seeds produced in the same place. To evaluate the physiological quality of the seeds, tests were carried out to determine the water content, germination and vigor. The analyzes were performed in the Multidisciplinary II laboratory. The experimental design used was completely randomized, with the treatments arranged in a $2 \times 6$ factorial scheme, having as factors the spacing between rows (25 and $50 \mathrm{~cm})$ and numbers of plants per linear meter $(4,8,12,16,20$ and 24 plants), and four replications. The
\end{abstract}

\footnotetext{
${ }^{1}$ Doutorando, Programa de Pós Graduação em Agronomia, Universidade Estadual do Oeste do Paraná, Campus Marechal Cândido Rondon, Marechal Cândido Rondon, Paraná, Brasil. E-mail: edvan_costa@outlook.com,wmmenechini@hotmail.com.

2 Docente, Programa de Pós Graduação em Produção Vegetal, Universidade Estadual de Goiás, Campus Ipameri, Ipameri, Goiás, Brasil. E-mail: nei.peixoto48@gmail.com.

${ }^{3}$ Professora substituta, Universidade Estadual de Maringá, Campus Regional de Umuarama, Umuarama, Paraná, Brasil. E-mail: nathy.a@hotmail.com.

${ }^{4}$ Mestra, Programa de Pós-Graduação em Produção Vegetal, Universidade Estadual de Goiás, Campus Ipameri, Ipameri, Goiás, Brasil. E-mail: natcassiadefaria@gmail.com, carolgallvao@hotmail.com.

${ }^{5}$ Mestrando, Programa de Pós-Graduação em Agronomia, Universidade Estadual do Oeste do Paraná, Campus Marechal Cândido Rondon, Marechal Cândido Rondon, Paraná, Brasil. E-mail: willian_haje@hotmail.com.
} 
tests were carried out with seeds stored for six months. According to the results of the analysis of variance, the first germination count, shoot length, root length and electrical conductivity there was significant interaction between the factors studied. The dry mass of seedlings had a significant effect on the spacing between rows and number of plants per linear meter in isolation. For the mass of a thousand seeds, accelerated aging, emergence of seedlings in sand and emergence speed index, there was a significant isolated effect only for the spacing between rows. Germination was not influenced by the spacing between rows and number of plants per linear meter. The spacing between rows of $50 \mathrm{~cm}$, with 24 linear $\mathrm{m}^{-1}$ plants between rows, showed better physiological potential, evidenced by the mass of a thousand seeds and electrical conductivity. Seeds in Vigna radiata produced in the spacing between rows of $50 \mathrm{~cm}$ and with 24 linear plants $\mathrm{m}^{-1}$, have better physiological potential.

Keywords: germination, Mung bean, plant arrangement, seed vigor.

\section{INTRODUÇÃO}

As leguminosas são as principais fontes de proteínas a alimentação humana, sendo ricas em energia, minerais e vitaminas (Choudhary et al. 2017). Dentre as leguminosas de maior produção mundial, destaca-se o feijão mungo (Vigna radiata (L.) Wilczek), de origem asiática, cultivado em todo o continente, com maior produção na Índia (Zhang et al., 2013; Somta et al., 2014).

Suas sementes exercem papel importante na dieta humana pelo seu alto valor nutritivo, por abranger $51 \%$ de carboidratos, excelente fonte de proteína (24-26\%), mineral (4\%), vitaminas $(3 \%)$, além de alto teor de ferro, aminoácidos, alta digestibilidade e propriedades antiflatulência (Mondal et al., 2011).

A utilização de sementes de qualidade, é um dos fatores que mais contribui para a obtenção de alta produtividade das culturas agrícolas (Amaro et al., 2015). Porém, considera-se que aproximadamente $89 \%$ dos produtores brasileiros de feijão utilizem sementes salvas para o plantio, ou seja, sementes certificadas. (Michels et al., 2014), tornando a plantação mais suscetível às condições adversas. Para garantir a qualidade de brotos de feijão, as sementes devem ser de qualidade, com alta pureza e vigor, isentas de doenças, sem contaminação por outras espécies e por defensivos agrícolas, além de terem pouco tempo de armazenamento.

O espaçamento e a população de plantas têm influência sobre a ocorrência e desenvolvimento de doenças nas culturas, pois tem relação com a disseminação das unidades infectivas do patógeno e a formação de microclima na cultura, afetando a passagem do vento, o sombreamento do solo e alterando a umidade relativa do ar (Harms et al., 2015; Linhares et al., 2015).

A alta qualidade das sementes é obtida por meio do gerenciamento correto dos campos de produção e, especialmente, da efetuação da colheita no momento adequado, considerando o ponto de maturidade fisiológica, pois a permanência das sementes no campo após a maturidade fisiológica pode ser agregada a perdas na produtividade, germinação e vigor (Sousa et al., 2011).

O processo de deterioração das sementes após o ponto de maturidade fisiológica é inevitável, mas pode ser retardado dependendo das condições de armazenamento das sementes (Cardoso et al., 2012). Em geral, para a cultura do feijoeiro, o armazenamento é realizado em condições ambientais não controladas, além disso fatores inerentes à própria semente, como o teor de água, são importantes para determinar a longevidade dessas sementes (Silva et al., 2014).

A qualidade das sementes não pode ser otimizada pelo armazenamento, porém em condições de armazenamento a deterioração deve ser a mínima possível, tendo em vista manter o vigor e o poder germinativo por maior período possível (Goldfarb \& Queiroga, 2013).

Amaro et al. (2014) avaliando a qualidade fisiológica de sementes de diferentes cultivares de feijão em função de densidades populacionais, constataram que o aumento da densidade de semeadura não afeta a qualidade fisiológica de sementes de cultivares de feijão, com exceção para a cultivar Madrepérola, onde a densidade populacional em até 290 mil plantas ha ${ }^{-1}$ é adequada para produção de sementes de qualidade, nas condições estudadas. De acordo com Ghassemi-Golezani et al. (2012) o peso médio das sementes de cultivares de feijão rajado diminuiu significativamente a medida que a densidade de plantas aumentou, entretanto, o potencial fisiológico das sementes, medido pela porcentagem de germinação e peso seco das plântulas, não foi afetada pela densidade de plantas.

Embora existam estudos de população de plantas sobre a produtividade para o feijão mungo em outros países (Rafiei, 2009; Hossain et al., 2011; Singh et al., 2011), ainda não 
existe relatos para o manejo correto desse parâmetro quando se avalia a qualidade fisiológica das sementes armazenadas.

De maneira geral, são essenciais os conhecimentos de práticas culturais adequadas ao feijão mungo, no que diz respeito as respostas sobre o desempenho fisiológico de sementes, quando submetidas a diferentes espaçamentos entre fileiras e números de plantas por metro linear, pois são escassos os trabalhos na literatura para esse parâmetro.

Desta forma, objetivou-se avaliar a qualidade fisiológica de sementes de feijão mungo em função de espaçamento entre linhas e número de plantas por metro linear.

\section{MATERIAL E MÉTODOS}

Para avaliação da qualidade fisiológica das sementes de feijão mungo, foram realizados testes para determinação da qualidade fisiologica de sementes (teor de água, germinação e vigor de sementes) os quais foram realizados no laboratório multidisciplinar II da Universidade Estadual de Goiás - Câmpus Ipameri, em agosto de 2018.

Foram utilizadas sementes de feijão mungo da cultivar Esmeralda MGS, produzidas no município de Ipameri-GO. A colheita foi realizada em dois momentos, sendo a primeira no dia 23 de fevereiro de 2018, e a segunda no dia 10 de março de 2018. As sementes foram colhidas após atingir o ponto de maturidade fisiológica, no qual apresentaram alto teor de água (16-19\%). Foi realizada a secagem das mesmas em ambiente sombreado, até atingirem o teor de água entre 11 à $13 \%$ para cada tratamento, sendo as se- mentes armazenadas em garrafas pet em ambiente natural, ou seja, temperatura e umidade relativa não controlada para após este período ser testadas quanto sua qualidade fisiológica sob diferentes espaçamentos.

O delineamento experimental utilizado foi inteiramente casualizado, com os tratamentos dispostos em esquema fatorial $2 \times 6$, tendo como fatores os espaçamentos entre fileiras ( 25 e $50 \mathrm{~cm}$ ) e números de plantas por metro linear (4, 8, 12, 16, 20 e 24 plantas), com quatro repetições.

De acordo com a classificação de Koppen, o clima da região é tropical (Aw), com duas estações bem definidas, estação seca no inverno e chuvas no verão, com a ocorrência de períodos de estiagem durante a estação chuvosa (veranicos). A temperatura média do ar em todos os meses do ano é superior a $18^{\circ} \mathrm{C}$. O solo da área onde o experimento foi implantado é classificado como Latossolo Vermelho-Amarelo Distrófico (Santos et al., 2013).

A análise química do solo na camada de $0-20 \mathrm{~cm}$ de profundidade onde o experimento foi implatado foi realizada de acordo com a metodologia proposta por Embrapa (1997), obtendo-se os seguintes resultados: $\mathrm{pH}$ em $\mathrm{CaCl}_{2}=4,91 ; \mathrm{P}$ disponível (extrator Mehlich 1) =8,6 $\mathrm{mg} \mathrm{dm}^{-3} ; \mathrm{K}$ disponível $=0,3 \mathrm{cmol}_{\mathrm{c}} \mathrm{dm}^{-3} ; \mathrm{Ca}=1,7 \mathrm{cmol}_{\mathrm{c}} \mathrm{dm}^{-3} ; \mathrm{Mg}=1,0 \mathrm{cmol}_{\mathrm{c}} \mathrm{dm}^{-3}$; $\mathrm{Al}=0,0 \mathrm{cmol}_{\mathrm{c}} \mathrm{dm}^{-3} ; \mathrm{H}+\mathrm{Al}, 4,0 \mathrm{cmol}_{\mathrm{c}} \mathrm{dm}^{-3}$; CTC 7,06 $\mathrm{cmol}_{\mathrm{c}}$ $\mathrm{dm}^{-3}$; e saturação por bases de $43,0 \%$.

Os dados referentes à precipitação pluviométrica (mm) e temperatura média $\left({ }^{\circ} \mathrm{C}\right)$, no período em que foi conduzido o experimento, estão apresentados nas Figuras 1 e 2 .

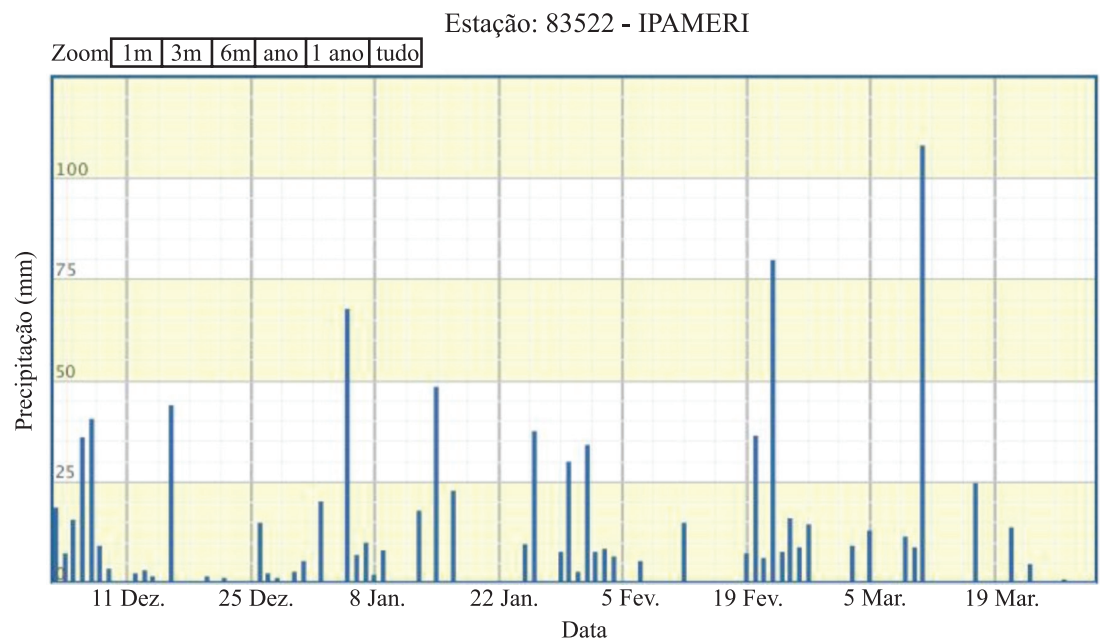

Figura 1 - Precipitação pluviométrica (mm) no município de Ipameri-GO entre dezembro de 2017 e março de 2018, quando o experimento em campo foi conduzido.

Fonte: INMET, 2018. 


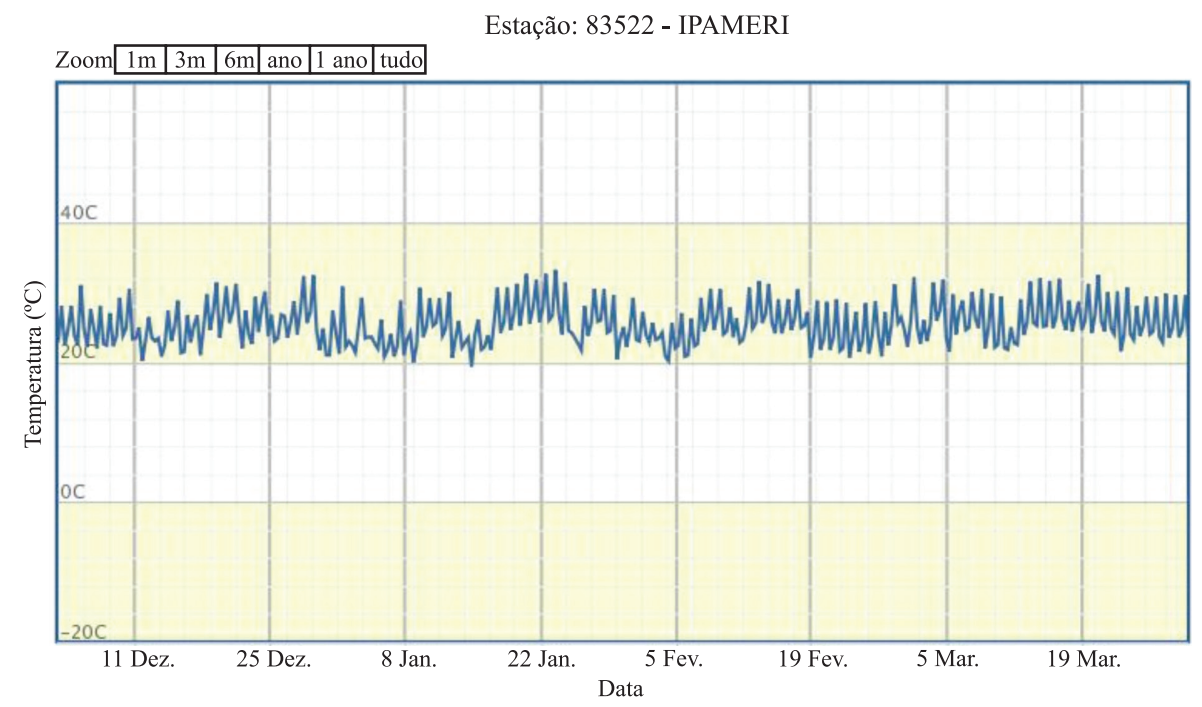

Figura 2 - Temperatura média $\left({ }^{\circ} \mathrm{C}\right)$ no município de Ipameri-GO entre dezembro de 2017 e março de 2018, quando o experimento em campo foi conduzido.

Fonte: INMET, 2018.

As unidades experimentais possuíam as seguintes dimensões: 4,0 $\mathrm{m}$ de comprimento e 2,5 $\mathrm{m}$ de largura, com área útil de $4 \mathrm{~m}^{2}$. O espaçamento de $50 \mathrm{~cm}$ foi composto por quatro fileiras, sendo consideradas as duas centrais como área útil e as duas laterais (uma do lado direito e outra do lado esquerdo) como bordaduras. O espaçamento de $25 \mathrm{~cm}$ foi composto por oito fileiras, sendo consideradas as quatro centrais como área útil e as duas laterais (dos lados esquerdo e direito) como bordaduras.

Para garantir a densidade desejada de plantas, a semeadura foi realizada com uma vez e meia da quantidade de sementes para cada densidade. Ao décimo dia foi realizado o desbaste de plântulas para ajustar as densidades desejadas. A semeadura ocorreu no dia 15 de dezembro de 2017. Um trator demarcou as linhas de semeadura e as sementes foram semeadas manualmente, na profundidade de $4 \mathrm{~cm}$. No plantio foram aplicados a lanço (manual) $600 \mathrm{~kg}$ $\mathrm{ha}^{-1}$ do fertilizante formulado 05-25-15, e aos 20 DAE (dia após emergência) foi realizada também a lanço a adubação de cobertura utilizando $150 \mathrm{~kg} \mathrm{ha}^{-1}$ de ureia em área total do experimento. Não foram feitos controles de pragas e doenças, e para o controle de plantas daninhas foram realizadas capinas manuais semanalmente.

A avaliação da qualidade das sementes foi realizada por meio dos seguintes testes e/ou determinações:

1 - Teor de água das sementes: utilizou-se o método da estufa a $105 \pm 3^{\circ} \mathrm{C}$ conforme metodologia prescrita nas Regras para Análise de Sementes - RAS (Brasil, 2009). Foram retiradas duas sub-amostras de 20 sementes por tratamento. Primeiramente a estufa foi regulada a temperatura de $105 \pm 3^{\circ} \mathrm{C}$, os recipientes foram secos por 30 minutos, posteriormente foram pesados em balança digital com três casas decimais com suas respectivas tampas e em seguida com as sementes. As amostras permaneceram na estufa por um período de 24 horas, e após esse período as amostras foram retiradas e mantidas em dessecador para reduzir a temperatura e pesadas. Os resultados foram expressos em porcentagem de teor de água (base úmida).

2 - Teste de germinação: foi conduzido com quatro repetições de 50 sementes por tratamento, sendo as sementes colocadas sobre duas folhas de papel "germitest" umedecidas com água destilada na proporção de 2,5 vezes o peso do papel seco e colocadas para germinar na temperatura de $25^{\circ} \mathrm{C}$, computando-se a porcentagem de plântulas normais aos sete dias. A avaliação foi efetuada de acordo com as Regras para Análise de Sementes RAS (Brasil, 2009). Os resultados foram expressos em porcentagem de plântulas normais por tratamento .

3 - Primeira contagem de germinação: foi conduzido juntamente com o teste de germinação, computando-se a porcentagem de plântulas normais aos cinco dias após o início instalação do teste, e os resultados expressos em porcentagem (\%). 
4 - Comprimento da parte aérea e raiz de plântulas: foram utilizadas dez plântulas normais após o teste de germinação para cada repetição. Mediu-se a parte aérea e raiz, com auxílio de régua graduada, sendo os resultados expressos em cm plântula ${ }^{-1}$.

5 - Massa seca de plântulas: foram avaliadas dez plântulas normais obtidas a partir do teste de germinação, excluindo destas os cotilédones. As repetições de cada tratamento foram acondicionadas em sacos de papel, identificados, e levados à estufa com circulação de ar forçada, mantida à temperatura de $80^{\circ} \mathrm{C}$ por um período de 24 horas. Após este período, cada repetição teve a massa seca avaliada em balança com precisão de 0,001g, e os resultados médios expressos em g.plântula ${ }^{-1}$.

6 - Massa de 1000 sementes: foi determinado conforme recomendações das Regras de Análise se Sementes - RAS (Brasil, 2009). Utilizou-se oito repetições de 100 sementes oriundas da porção semente pura de cada tratamento, onde cada amostra, foi pesada individualmente e as repetições que ficaram dentro do padrão foram multiplicadas por 10 , sendo os resultados expresso em $\mathrm{g}$.

7 - Condutividade elétrica: foi conduzido com quatro repetições de 50 sementes para cada tratamento, sendo que as sementes foram pesadas e imersas em $75 \mathrm{~mL}$ de água destilada e mantidas por 24 horas em germinador à $25^{\circ} \mathrm{C}$ (Carvalho et al., 2009). Após esse período foi avaliada a condutividade elétrica da solução em condutivímetro, sendo o resultado foi expresso em $\mu \mathrm{S} \mathrm{cm}^{-1} \mathrm{~g}^{-1}$.

8 - Envelhecimento acelerado: foram utilizadas 200 sementes por tratamento. As sementes foram dispostas em camada única sobre tela de alumínio no interior de caixas plásticas do tipo "gerbox", contendo $40 \mathrm{~mL}$ de água destilada no fundo e mantidas sob temperatura de $41{ }^{\circ} \mathrm{C}$ por um período de 48 horas. A avaliação do teste de germinação foi realizada no quinto dia após o início do teste, sendo os resultados expressos em porcentagem de plântulas normais, seguindo a metodologia descrita por Jianhua \& McDonald (1996).

9 - Teste de emergência de plântulas em areia: foi realizado em caixas plásticas, contendo 725 $\mathrm{g}$ de areia lavada, esterilizada (em autoclave a $120{ }^{\circ} \mathrm{C}$ por 2 horas) e umedecida com água destilada, visando atingir 60\% da capacidade de retenção (BRASIL, 2009). Foram distribuídas quatro repetições de 50 sementes por tratamento. A avaliação foi realizada até os quatorze dias após a instalação (Zucareli et al., 2015), sendo os resultados expressos em porcentagem de plântulas emersas.

10 - Índice de velocidade de emergência (IVE): foi realizado juntamente ao teste de emergência de plântulas em areia, sendo as avaliações realizadas diariamente desde o primeiro dia após a semeadura até o décimo quarto dia. A partir dos valores diários de plântulas emergidas foi calculado o índice de velocidade de emergência conforme Maguire (1962).

Os dados obtidos foram analisados através da análise de variância e regressão. A comparação das médias obtidas nos testes foi realizada através do teste de Tukey a 5\% de probabilidade para os espaçamentos entre fileiras e para os números de plantas por metro linear foram realizadas análise de regressão. As análises estatísticas foram processadas utilizando o software estatístico SISVAR (Ferreira, 2014).

\section{RESULTADOS E DISCUSSÃO}

Na Tabela 1, observa-se os valores médios dos teores de água das sementes armazenadas. Houve variação de $1,5 \%$ entre os tratamentos. A variação no teor de água ocorre em função do ambiente em que as sementes foram armazenadas tendo relação com as condições de temperatura e de umidade relativa (Juvino et al., 2014). Lembrando que o teor de água de aproximadamente 14\%, é o valor considerado adequado para o armazenamento de sementes de feijão (Boaigo, 2013).

Tabela 1 - Teor de água (\%) de sementes de feijão mungo produzidas em função de diferentes espaçamentos entre fileiras e número de plantas por metro linear, após armazenamento por seis meses. Ipameri-GO, 2019

\begin{tabular}{ccccccc}
\hline Tratamentos & \multicolumn{6}{c}{ Números de plantas por metro linear } \\
\hline $\begin{array}{c}\text { Espaçamentos } \\
(\mathrm{cm})\end{array}$ & 4 & 8 & 12 & 16 & 20 & 24 \\
\hline 25 & 13,4 & 12,8 & 13,0 & 12,5 & 13,1 & 12,9 \\
50 & 12,1 & 13,5 & 12,2 & 12,6 & 13,3 & 13,6 \\
\hline
\end{tabular}

Com base nos resultados da análise de variância, houve interação significativa entre os fatores estudados quando consideras as variáveis primeira contagem de germinação (Figura 3), comprimento de raiz (Figura 4), comprimento parte aérea (Figura 5), condutividade elétrica (Figura 7). A massa seca de plântulas (Figura 6) apresentou efeito significativo para os espaçamentos entre fileiras e números de plantas por metro linear. Para a massa de mil sementes, envelhecimento acelerado, emergência de plântulas em areia e índice de emergência, verificou-se 
efeito significativo isolado apenas para os espaçamentos entre fileiras. A germinação não foi influenciada pelos espaçamentos entre fileiras e números de plantas por metro linear.

Nota-se que a primeira contagem de germinação de sementes no espaçamento de $25 \mathrm{~cm}$ se ajustou ao modelo de regressão linear decrescente (Figura 3), atingindo menor resultado de $76 \%$ de sementes germinadas com 24 plantas $\mathrm{m}^{-1}$, sendo $6 \%$ menor que a percentagem registrada para o de 4 plantas $\mathrm{m}^{-1}(81 \%)$. No espaçamento de $50 \mathrm{~cm}$, os dados ajustaram-se ao modelo de regressão quadrática, observouse um menor desempenho de percentagem de germinação no ponto de mínimo verificado para o número de plantas $\mathrm{m}^{-1}$ estimada equivalente a 12 plantas $\mathrm{m}^{-1}(79 \%)$ (Figura 3$)$.

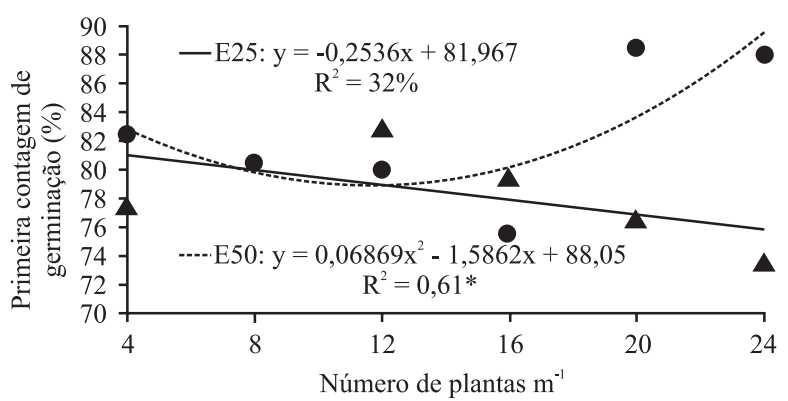

Figura 3 - Primeira contagem de germinação de feijão mungoproduzido em função de diferentes espaçamentos entre fileiras e número de plantas por metro linear, a partir de sementes armazenadas por seis meses. Ipameri-GO, 2019.

*Significativo a $5 \%$ de probabilidade pelo teste de TUKEY.

Observa-se que para o comprimento de raiz entre o número de plantas por metro linear no espaçamento de $25 \mathrm{~cm}$ (Figura 4), os valores se ajustaram a regressão linear crescente, atingindo maior comprimeto de raiz $(5,78 \mathrm{~cm})$ com 24 plantas $\mathrm{m}^{-1}$, sendo $26,30 \%$ maior que o comprimento de raiz registrado para a densidade de 4 plantas $\mathrm{m}^{-1}(4,26$ $\mathrm{cm})$. No espaçamento de $50 \mathrm{~cm}$, os valores se ajustaram a regressão linear decrescente, atingindo menor resultado $(4,37 \mathrm{~cm})$ com 24 plantas $\mathrm{m}^{-1}$, sendo $25,42 \%$ menor que o comprimento de plântulas parte raiz registrado para o de 4 plantas $\mathrm{m}^{-1}(5,86 \mathrm{~cm})$ (Figura 4).

A avaliação do comprimento das plântulas e/ou de suas partes é uma característica importante na diferenciação de lotes de sementes, onde os maiores valores correspondem aos lotes de maior vigor, sendo o comprimento de plântulas sensível para classificar lotes com diferenças sutis no potencial fisiológico (Guedes et al., 2009).

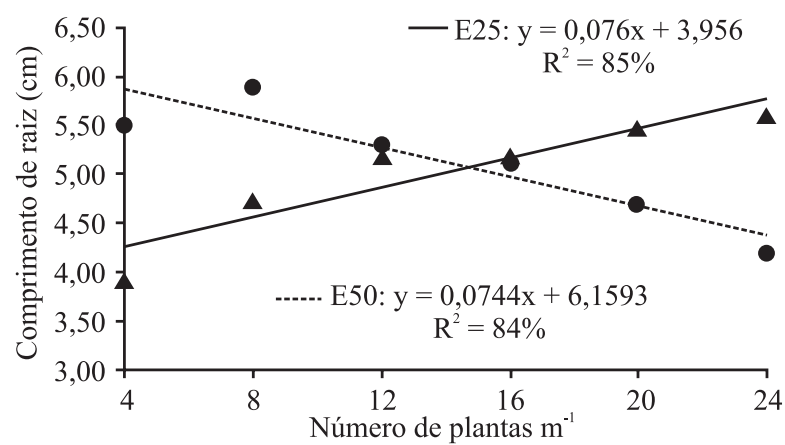

Figura 4 - Comprimento de raiz de feijão mungo produzido em função de diferentes espaçamentos entre fileiras e número de plantas por metro linear, a partir de sementes armazenadas por seis meses. Ipameri-GO, 2019.

*Significativo a $5 \%$ de probabilidade pelo teste de TUKEY.

Verifica-se que para o comprimento da parte aérea, o número de plantas por metro linear no espaçamento de 25 cm (Figura 5), os dados se ajustaram ao modelo de regressão quadrática, ocorrendo incremento nos resultados até 15,02 $\mathrm{cm}$, com o ponto de máximo comprimento de parte aérea com 23 plantas $\mathrm{m}^{-1}$. No espaçamento de $50 \mathrm{~cm}$, a curva de regressão se ajustou ao modelo de regressão quadrática, observando maior desempenho de comprimento da parte aérea no ponto de máximo verificado para o número de plantas $\mathrm{m}^{-1}$ estimada equivalente a 8 plantas $\mathrm{m}^{-1}(15,54 \mathrm{~cm})$ (Figura 5).

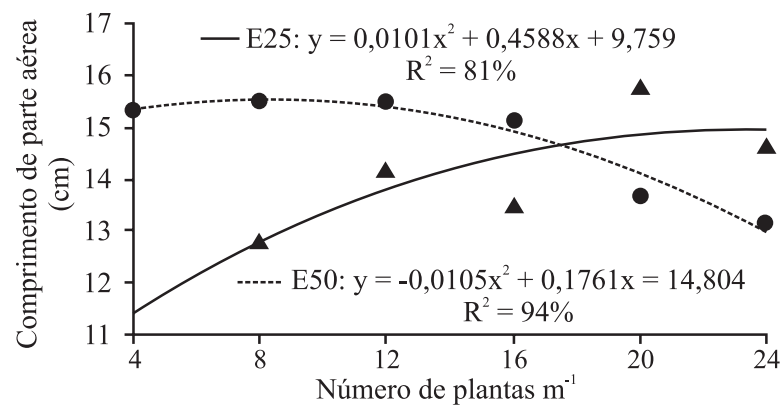

Figura 5 - Comprimento de plântulas parte aérea de feijão mungo produzido em função de diferentes espaçamentos entre fileiras e número de plantas por metro linear, a partir de sementes armazenadas por seis meses. Ipameri-GO, 2019.

*Significativo a $5 \%$ de probabilidade pelo teste de TUKEY. 
A elevação do autossombreamento nos tratamentos em que havia maior número de plantas por metro linear pode estimular maior comprimento da parte aérea das plantas e promover redução momentânea no desenvolvimento do sistema radicular (Sampaio et al., 2018). Isso acontece porque a planta altera sua relação fonte-dreno, enviando mais fotoassimilados para a parte aérea em detrimento da raiz, até que a parte aérea passe a interceptar luz suficiente para que sua produção normal de fotoassimilados seja reestabelecida. De acordo com Taiz et al. (2017), as plantas apresentam mecanismos de autorregulação para responder a fatores externos, como competição por luz, água e nutrientes, o que influencia no particionamento dos fotoassimilados

Para a massa seca das plântulas de feijão mungo, o espaçamento de $50 \mathrm{~cm}\left(0,28 \mathrm{~g}_{\text {planta- }}{ }^{2}\right)$ diferiu-se estatiscamente como melhor, apresentando maior média em relação ao espaçamento de $25 \mathrm{~cm}\left(0,24\right.$ g planta- $\left.^{1}\right)$ (Figura $6)$. Houve efeito significativo para os números de plantas por metro linear, onde os valores se ajustaram a regressão linear crescente, atingindo maior massa seca de plântulas de 0,28 g planta- $^{-1}$ com 24 plantas $\mathrm{m}^{-1}$, sendo $14,28 \%$ maior que a massa seca registrada para o de 4 plantas $\mathrm{m}^{-1}(0,24 \mathrm{~g}$ planta- $^{1}$ ) (Figura 6).

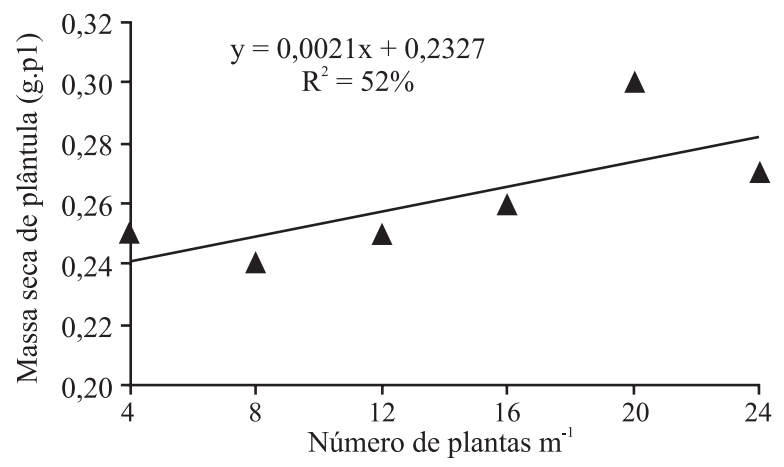

Figura 6 - Massa seca de plântulas de feijão mungo produzido em função de diferentes espaçamentos entre fileiras e número de plantas por metro linear, a partir de sementes armazenadas por seis meses. Ipameri-GO, 2019.

*Significativo a $5 \%$ de probabilidade pelo teste de TUKEY.

Provavelmente, este aumento ocorreu em virtude da eficiência de utilização da energia solar que, com o aumento da população de plantas, foi mais bem distribuída sobre as folhas, resultando em maior concentração de assimilados nas sementes. Segundo Carvalho \& Nakagawa (2012), as sementes vigorosas proporcionam maior transferência de reserva para o eixo embrionário, na fase de germinação, originando plântulas com maior peso em função do maior acúmulo de matéria seca.

A condutividade elétrica, no espaçamento de $50 \mathrm{~cm}$ $\left(97,64 \mu \mathrm{S} . \mathrm{cm}^{-1} \cdot \mathrm{g}^{-1}\right)$ diferiu-se estatiscamente como melhor, apresentando maior média em relação ao espaçamento de $25 \mathrm{~cm}\left(107,47 \mu \mathrm{S} . \mathrm{cm}^{-1} \cdot \mathrm{g}^{-1}\right)$. No desdobramento, apenas o espaçamento de $25 \mathrm{~cm}$ mostrou-se significativo, ajustandose ao modelo de regressão linear decrescente (Figura 7), atingindo menor resultado de $88,76 \mu \mathrm{S} . \mathrm{cm}^{-1} . \mathrm{g}^{-1}$ com 24 plantas $\mathrm{m}^{-1}$, sendo $30,40 \%$ menor que a condutividade elétrica registrada para o de 4 plantas $\mathrm{m}^{-1}\left(127,52 \mu \mathrm{S} \cdot \mathrm{cm}^{-1} \cdot \mathrm{g}^{-1}\right)$.

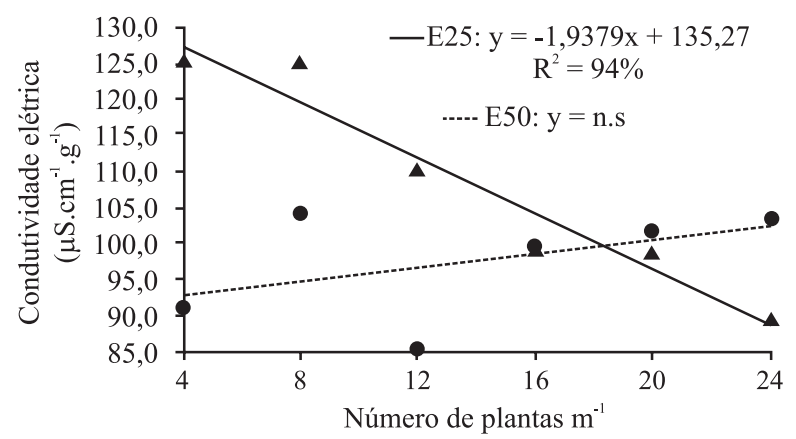

Figura 7 - Condutividade elétrica de sementes de feijão mungo, produzidas em função de diferentes espaçamentos entre fileiras e número de plantas por metro linear, após armazenamento por seis meses. Ipameri-GO, 2019.

*Significativo a $5 \%$ de probabilidade pelo teste de TUKEY.

Tais resultados são opostos aos encontrados por Costa et al. (2008), quando avaliaram a qualidade fisiológica de sementes de feijoeiro em função de três populações de plantas. Os autores afirmam que o teste de condutividade elétrica, não demonstrou interferência nas populações de plantas. No entanto, Punia et al. (2018) avaliando a qualidade fisiológica de sementes de quinze genótipos de feijão mungo, concluíram que o teste de condutividade elétrica, pode ser usado como preditor confiável de germinação padrão e estabelecimento de plântulas para a espécie.

\section{CONCLUSÃO}

As sementes de feijão mungo produzidas em 24 plantas $\mathrm{m}^{-1}$ linear e espaçamento de $50 \mathrm{~cm}$ entre fileiras, apresentam melhor potencial fisiológico. 


\section{LITERATURA CITADA}

AMARO, H.T.R.; DAVID, A.M.S.S.; ASSIS, M.O.; RODRIGUE, B.R.A.; CANGUSSÚ, L.V.S.; OLIVEIRA, M.B. Testes de vigor para avaliação da qualidade fisiológica de sementes de feijoeiro. Revista de Ciências Agrárias, v.38, n.3, p.383-389, 2015.

AMARO, H.T.R.; DAVID, A.M.S.S.; CARVALHO, J.; VIEIRA, N.M.B.; ASPIAZÚ, I.; ASSIS, M.O. Qualidade fisiológica de sementes de cultivares de feijão em função de densidades populacionais. Semina: Ciências Agrárias, v.35, n.3, p.1241-1248, 2014.

BOIAGO, N.P.; FORTES, A.M.T.; KULZER, S.R.; KOELLN, F.T.S. Potencial fisiológico de sementes armazenadas de cultivares de feijão-caupi produzidas no estado do paraná. Revista Varia Scientia Agrárias, v.3, n.2, p.21-32, 2013.

BRASIL. Ministério da Agricultura, Pecuária e Abastecimento. Regras para análise de sementes. Ministério da Agricultura, Pecuária e Abastecimento. Secretaria de Defesa Agropecuária. Brasília, DF: Mapa/ ACS, 2009. 395p.

CARDOSO, R.B.; BINOTTI, F.F.S.; CARDOSO, E.D. Potencial fisiológico de sementes de crambe em função de embalagens e armazenamento. Pesquisa Agropecuária Tropical, v.42, n.3, p.272-278, 2012.

CARVALHO, N.M.; NAKAGAWA, J. Sementes: ciência, tecnologia e produção. Jaboticabal: FUNEP, 2012. 590p.

CARVALHO, L.F.; SEDIYAMA, C.S.; REIS, M.S.; DIAS, D.C.F.S.; MOREIRA, M.A. Influência da temperatura de embebição da semente de soja no teste de condutividade elétrica para avaliação da qualidade fisiológica. Revista Brasileira de Sementes, v.31, n.1, p.9-17, 2009.

CHOUDHARY, M.; JAT, H.L.; BIJARNIYA, S.; BHATI, $\mathrm{V}$. Adoption of mungbean production technology by the farmers in Jaipur district of Rajasthan, India. International Journal of Current Microbiology and Applied Sciences, v.6, n.4, p.739-743, 2017.

COSTA, R.S.S.; SÁ, M.E.; ORIOLI JÚNIOR, V.; BERTOLIN, D.C. Qualidade fisiológica de sementes de feijão em função da população de plantas e nitrogênio em plantio direto. Nucleus, v.5, n.2, p.335-344, 2008.

EMPRESA BRASILEIRA DE PESQUISA AGROPECUÁRIA - EMBRAPA. Centro Nacional de Pesquisa de Solos. Manual de métodos de análise de solo. 2.ed. Brasília, 1997. 212p.

FERREIRA, D.F. Sisvar: a Guide for its Bootstrap procedures in multiple comparisons. Ciência $e$ Agrotecnologia, v.38, n.2, p.109-112, 2014.
GHASSEMI-GOLEZANI, K.; AKBARI, H.; BANDEHHAGH, A. Effects of plant density and pod position on seed vigour of pinto bean cultivars. Research on Crops, v.13, n.2, p.529-533, 2012.

GOLDFARB, M.; QUEIROGA, V.P. Considerações sobre o armazenamento de sementes. Tecnologia e Ciência Agropecuária, João Pessoa, v.7, n.3, p.71-74, 2013.

GUEDES, R.S.; ALVES, E.D.; GONÇALVES, E.P.; VIANA, J.S.; MEDEIROS, M.S.; LIMA, C.R. Teste de comprimento de plântula na avaliação da qualidade fisiológica de sementes de Erythrina velutina Willd. Semina: Ciências Agrárias, v.30, n.4, p.793-802, 2009.

HARMS, M.G.; DALLA PRIA, M.; REZENDE, B.L.; PRESTES; A.M.C.; DALAZOANA, F. Influência da densidade de plantas e do uso de fungicida nas doenças foliares e na produtividade de cebola. Horticultura Brasileira, v.33, n.2, p.203-207, 2015.

HOSSAIN, M.K.; ALI, M.H.; UDDIN, A.F.M.J. Influence of plant population on growth and yield of summer mungbean (Vigna radiata). Bangladesh Research Publications Journal, v.6, n.2, p.167-173, 2011.

INMET,INSTITUTONACIONALDEMETEOROLOGIA. Estações Convencionais - Gráficos. Disponível em: http:// www.inmet.gov.br/portal/index.php? $\mathrm{r}=\mathrm{h}$ _estacoes_conv_ graf $>$. Acesso em 23 de ago. de 2018.

JIANHUA, Z.; MCDONALD, M.B. The saturated salt accelerated aging test for small seed crops. Seed Science and Technology, v.25, n.1, p.123-131, 1996.

JUVINO, A.N.K.; RESENDE, O.; COSTA, L.M.; SALES, J.F. Vigor da cultivar BMX Potência RR de soja durante o beneficiamento e períodos de armazenamento. Revista Brasileira de Engenharia Agrícola e Ambiental, v.18, n.8, p.844-850, 2014.

LINHARES, P.C.F.; OLIVEIRA, J.D.; ALMEIDA, A.M.B.; NEVES, A.P.M.; CUNHA, L.M.M.; PAIVA, A.C.C.; PEREIRA, B.B.M.; MEDEIROS, A.P. Espaçamento e densidades de plantas no surgimento de doenças e pragas e no estiolamento do coentro. Intesa, v.9, n.1, p.35-38, 2015.

MAGUIRE, J.D. Speed of germination aid in selection and evaluation for seeding and vigour. Crop Science, v.2, n.2, p.176-177, 1962.

MICHELS, A.F.; SOUZA, C.A.; COELHO, C.M.M.; ZALIO. M. Qualidade fisiológica de sementes de feijão crioulo produzidas no oeste e planalto catarinense. Revista Ciência Agronômica, v.45, n.3, p.620-632, 2014.

MONDAL, M.M.A.; HAKIM, M.A.; JURAIMI, A.S.; AZAD, M.A.K.; KARIM, M.R. Contribution of 
morphophysiological attributes in determining the yield of mungbean. African Journal of Biotechnology, v.10, n.60, p.12897-12904, 2011.

PUNIA, J.R.C.; BRUKAR, P.A.; SANGWAN, V.P.S. Association among different seed quality parameters in mungbean (Vigna radiata L. Wilczek). International Journal of Pure \& Applied Bioscience, v.6, n.2, p.742-746, 2018.

RAFIEI, M. Influence of tillage and plant density on mungbean. American-Eurasian Journal of Sustainable Agiculture, v.3, n.4, p.877-880, 2009.

SAMPAIO, I.M.G.; GUIMARÃES, M.A.; LEMOS NETO, H.S.; MAIA, C.L.; VIANA, C.S.; GUSMÃO, S.A.L. Pode o uso de mudas agrupadas e a maior densidade de plantio aumentar a produtividade de jambu? Revista de Ciencias Agrárias, v.61, n.1, p.1-8, 2018.

SANTOS, H.G.; ALMEIDA, J.A.; OLIVEIRA, J.B.; LUMBRERAS, J.F.; ANJOS, L.H.C.; COELHO, M.R.; JACOMINE, P.K.T.; CUNHA, T.J.F.; OLIVEIRA, V.A. Sistema Brasileiro de Classificação de Solos. 3.ed. Brasília: Embrapa, 2013. 342p.

SILVA, M.M.; SOUZA, H.R.T.; DAVID, A.M.S.S.; SANTOS, L.M.; SILVA, R.F.; AMARO, H.T.R. Qualidade fisiológica e armazenamento de sementes de feijão-comum produzidas no norte de Minas Gerais. Revista Agro@, mbiente, v.8, n.1, p.97-103, 2014.

SINGH, G.; SEKHON, H.S.; SINGH, G.; BRAR, J.S.; BAINS, T.S.; SHANMUGASUNDARAM, S. Effect of plant density on the growth and yield of mungbean
[Vigna radiata (L.) Wilczek] genotypes under different environments in India and Taiwan. International Journal of Agricultural Research, v.6, n.7, p.573-583, 2011.

SOMTA, P.; PRATHET, P.; ALISA KONGJAIMUN, A.; SRINIVES, P. Dissecting quantitative trait loci for agronomic traits responding to iron deficiency in mungbean [Vigna radiata (L.) Wilczek]. Agrivita, v.36, n.2, p.101111, 2014.

SOUSA, T.V.; ALKIMIM, E.R.; DAVID, A.M.S.S.; SÁ, J.R.; PEREIRA, G.A.; AMARO, H.T.R.; MOTA, W. Época de colheita e qualidade fisiológica de sementes de coentro produzidas no norte de Minas Gerais. Revista Brasileira de Plantas Medicinais, v.13, n.5, p.591-597, 2011.

TAIZ, L.; ZEIGER, E.; MOLLER, I.M.; MURPHY, A. Fisiologia e desenvolvimento vegetal. 6.ed. Editora Artimed: Porto Alegre, 2017. 888p.

ZHANG, X.; SHANG, P.; QIN, F.; ZHOU, Q.; GAO, B.; HUANG, H.; YANG, H.; SHI, H.; YU, L. Chemical composition and antioxidative and anti-inflammatory properties of ten commercial mung bean samples. LWT Food Science and Technology, v.54, n.1, p.171-178, 2013.

ZUCARELI, C.; BRZEZINSKI, C.R.; ABATI, J.; WERNER, F.; RAMOS JÚNIOR, E.U.; NAKAGAWA, J. Qualidade fisiológica de sementes de feijão carioca armazenadas em diferentes ambientes. Revista Brasileira de Engenharia Agricola e Ambiental, v.19, n.8, p.803-809, 2015 .

Recebido para publicação em 01/02/2020, aprovado em 15/04/2020 e publicado em 30/04/2020. 